\title{
BMJ Open Glycaemic durability with dipeptidyl peptidase- 4 inhibitors in type 2 diabetes: a systematic review and meta-analysis of long-term randomised controlled trials
}

\author{
Katherine Esposito, ${ }^{1}$ Paolo Chiodini, ${ }^{2}$ Maria Ida Maiorino, ${ }^{3}$ Giuseppe Bellastella, ${ }^{3}$ \\ Annalisa Capuano, ${ }^{4}$ Dario Giugliano ${ }^{3}$
}

To cite: Esposito K, Chiodini P, Maiorino MI, et al. Glycaemic durability with dipeptidyl peptidase-4 inhibitors in type 2 diabetes: a systematic review and metaanalysis of long-term randomised controlled trials. BMJ Open 2014;4:e005442. doi:10.1136/bmjopen-2014005442

- Prepublication history and additional material is available. To view visit the journal (http://dx.doi.org/10. 1136/bmjopen-2014005442)

Received 10 April 2014 Accepted 27 May 2014

CrossMark

For numbered affiliations see end of article.

Correspondence to Dr Dario Giugliano; dario.giugliano@unina2.it

\section{ABSTRACT}

Objectives: To evaluate glycaemic durability with dipeptidyl peptidase-4 (DPP-4) inhibitors in type 2 diabetes.

Design: A systematic review and meta-analysis of longterm randomised trials of DPP-4 inhibitors on haemoglobin A1c (HbA1c) was conducted. Electronic searches were carried out on the following databases: MEDLINE, EMBASE, Scopus and Web of Knowledge to December 2013. Searches were supplemented by a review of trial registries and references from identified trials. Trials were included if they lasted at least 76 weeks, and had intermediate and final assessments of $\mathrm{HbA} 1 \mathrm{c}$. Citations and full-text articles were screened by two reviewers. A random effect model was used to pool data.

Participants: Adults with type 2 diabetes. Interventions: Any DPP-4 inhibitor (sitagliptin, vildagliptin, saxagliptin, linagliptin and alogliptin).

Outcome measures: The difference between final and intermediate $\mathrm{HbA1c}$ assessment was the primary outcome.

Results: We screened 461 citations and reviewed 12 articles reporting 12 trials in 14829 participants. All trials were of 76 weeks duration at least. The difference in $\mathrm{HbA1c}$ changes between final and intermediate points averaged $0.22 \%(95 \% \mathrm{Cl} 0.15 \%$ to $0.29 \%)$, with high heterogeneity $\left(l^{2}=91 \%, p<0.0001\right)$. Estimates of differences were not affected by the analysis of six extension trials $(0.24 \%, 0.02$ to 0.46$)$, or five trials in which a DPP-4 inhibitor was added to metformin $(0.24 \%$, 0.16 to 0.32 ).

Conclusions: There is evidence that the effect of DPP-4 inhibitors on $\mathrm{HbA1c}$ in type 2 diabetes significantly declines during the second year of treatment. Future research should focus on the characteristics of patients that benefit most from DPP-4 inhibitors in terms of glycaemic durability.

\section{INTRODUCTION}

The optimal drug sequence after metformin failure is an area of uncertainty. ${ }^{1}{ }^{2}$ Sulfonylureas are the most commonly added

\section{Strengths and limitations of this study}

- It is the first systematic review of randomised trials assessing the glucose-lowering effect of dipeptidyl peptidase-4 (DPP-4) inhibitors as a function of time in trials with a long follow-up.

- The statistical power of our attempts to pool data is supported by a sufficient number of trials published until now and the relatively high number of participants in the published trials.

- There is high heterogeneity in primary analysis and sensitivity or subgroup analyses.

- Available evidence to individualise the characteristics of the patient with diabetes who benefits most from DPP-4 inhibitors in terms of glycaemic durability is limited.

oral antidiabetic drugs in this scenario ${ }^{3}$; the dipeptidyl-peptidase 4 (DPP-4) inhibitors may offer a non-inferior glucose-lowering efficacy, with a reduced risk of hypoglycaemia and weight gain. ${ }^{4}$ Moreover, DPP-4 inhibitors may protect pancreatic $\beta$-cells from enhanced apoptosis in animal models of diabetes, ${ }^{5}$ and also improve several markers of $\beta$-cell function in type 2 diabetes. ${ }^{6}$ Intuitively, a positive influence of DPP-4 inhibitors on islet function may attenuate the inherently progressive nature of $\beta$-cell loss.

We hypothesised that durability of glycaemic control may be a surrogate marker to test the hypothesis that DPP-4 inhibitors influence $\beta$-cell loss: randomised trials evaluating the long-term (up to 108 weeks) effect of DPP-4 inhibitors on haemoglobin A1c (HbAlc) level are available and may be used as an indicator of glycaemic durability.

\section{METHODS}

Eligibility criteria

We followed the PRISMA (Preferred Reporting Items for Systematic reviews and 
Meta-Analyses) checklist for reporting systematic reviews and meta-analyses. ${ }^{7}$ We carried out this systematic review in accordance with the study protocol (see online supplementary appendix 1). Peer-reviewed journal articles and conference abstracts that reported the results of a randomised controlled trial and met the following eligibility criteria were eligible for inclusion: (1) trials reporting the effect of DPP-4 inhibitors (sitagliptin, vildagliptin, saxagliptin, linagliptin, alogliptin) on the HbAlc level in participants with type 2 diabetes who were either drug naïve, or on background therapy with metformin or other oral agents; (2) lasting at least 76 weeks and (3) having final and intermediate assessment of $\mathrm{HbAlc}$, with the intermediate point assessed between 24 and 52 weeks. We have shown that the relation between the HbAlc response to DPP-4 inhibitors and time is quite linear until between 24 and 52 weeks. ${ }^{8}$ We included primary trials and extension trials. We excluded trials if the intervention included the initiation of two agents at the same time, and the doses of DPP-4 inhibitors were different from those approved in the clinical practice (sitagliptin, $100 \mathrm{mg}$ once daily; vildagliptin, $50 \mathrm{mg}$ twice daily; saxagliptin, $5 \mathrm{mg}$ once daily; linagliptin, $5 \mathrm{mg}$ once daily; alogliptin, $25 \mathrm{mg}$ once daily). The search had no language restriction; however, we excluded reviews, editorials, comments, letters and abstracts.

\section{Search strategy}

We performed an electronic search for randomised trials evaluating DPP-4 inhibitors in patients with type 2 diabetes through December 2013. We searched MEDLINE, EMBASE, Scopus and Web of Knowledge using the following terms as Medical Subject Heading and keywords: type 2 diabetes (T2DM, NIDDM, non-insulin-dependent diabetes), glycated haemoglobin (haemoglobin A1c, HbA1c, A1C), DPP-4 inhibitors (sitagliptin, vildagliptin, saxagliptin, linagliptin, alogliptin), clinical trials. We searched for additional trials in the prescribing information documents of approved medications, at relevant web sites (eg, http://www.clinicalstudy results.org and http://www.clinicaltrials.gov), and in personal reference lists of recovered articles.

\section{Study selection, data extraction and quality assessment}

The relevance of studies was assessed with a hierarchical approach on the basis of title, abstract and the full manuscript. Two reviewers (KE and DG) independently screened the titles and abstracts of identified citations to select those requiring full-text assessment. Where there was disagreement, a third reviewer (MIM) assessed the records to reach a consensus. Full-text articles were further assessed and data were entered into a prespecified table that included information on authors, year of publication, sample size, type of DPP-4 inhibitor, duration of follow-up, comparator drug, baseline HbAlc and outcomes. Of the selected trials, only study arms assessing the efficacy of DPP-4 inhibitors were included in the analysis, whereas any other arm (placebo or comparator drug) of the same trial was excluded.

\section{Data analysis}

We used the Cochrane Collaboration's tool to assess risk of bias at the outcome level. ${ }^{9}$ Bias was assessed in duplicate with disagreements resolved by a third reviewer. The assessed domains were random sequence generation, allocation concealment, blinding of participants and personnel, blinding of outcome assessment and completeness of outcome data.

We used the difference between decrease of HbAlc from baseline at the end of follow-up (76-104 weeks) versus A1C decrease at intermediate assessments (2452 weeks) during DPP-4 inhibitor administration as an index of glycaemic durability. The difference between final and intermediate HbAlc assessment was the primary end point. To calculate the overall difference between the two periods, each study was weighted by the reciprocal of the variance for HbAlc change. In a conservative approach, the random-effect estimates of mean differences, which allow for variation of true effects across studies, were taken as 'main results'. Because variances for HbA1c change between final and intermediate end points were not directly reported, they were calculated by assuming a correlation coefficient of 0.5 . A sensitivity analysis was performed assuming a correlation of 0.25 and 0.75 ; subgroup analyses were also performed for primary trials, extension trials and 'add-on' metformin trials. Heterogeneity between studies was assessed by using $Q$ statistic and $\mathrm{I}^{2} .{ }^{10} \mathrm{~A} p$ value of $\mathrm{Q}$ statistic less than 0.10 was considered significant. Data were analysed using Stata, V.11.0 (Stata Corp., College Station, Texas, USA).

\section{RESULTS}

A total of 751 citations were identified (figure 1) from electronic searches. A further 11 relevant publications were identified as cited by included trial reports. After removing duplicates, we screened 461 citations. Based on the title and abstract, 447 were assessed as ineligible. The full text of the remaining 14 articles was assessed for eligibility. Further assessment of these articles revealed that two did not meet the inclusion criteria, one because the dose of saxagliptin was twofold higher than the recommended $5 \mathrm{mg}$ daily dose, ${ }^{11}$ and the other because the intermediate Hblc assessment occurred at 12 weeks. ${ }^{12}$

\section{Duration and settings}

A total of 12 articles were eligible for inclusion. ${ }^{13-24}$ All studies were randomised controlled trials (table 1); most trials were multinational and sponsored by industry. The trials were published between 2008 and 2013. Six trials $^{19-24}$ were an extension of previous randomised trials (table 1). All trials were double blind, including the six extension trials.

\section{Intervention}

All trials assessed the effect of a DPP-4 inhibitor versus placebo or a comparator drug on HbAlc level in 


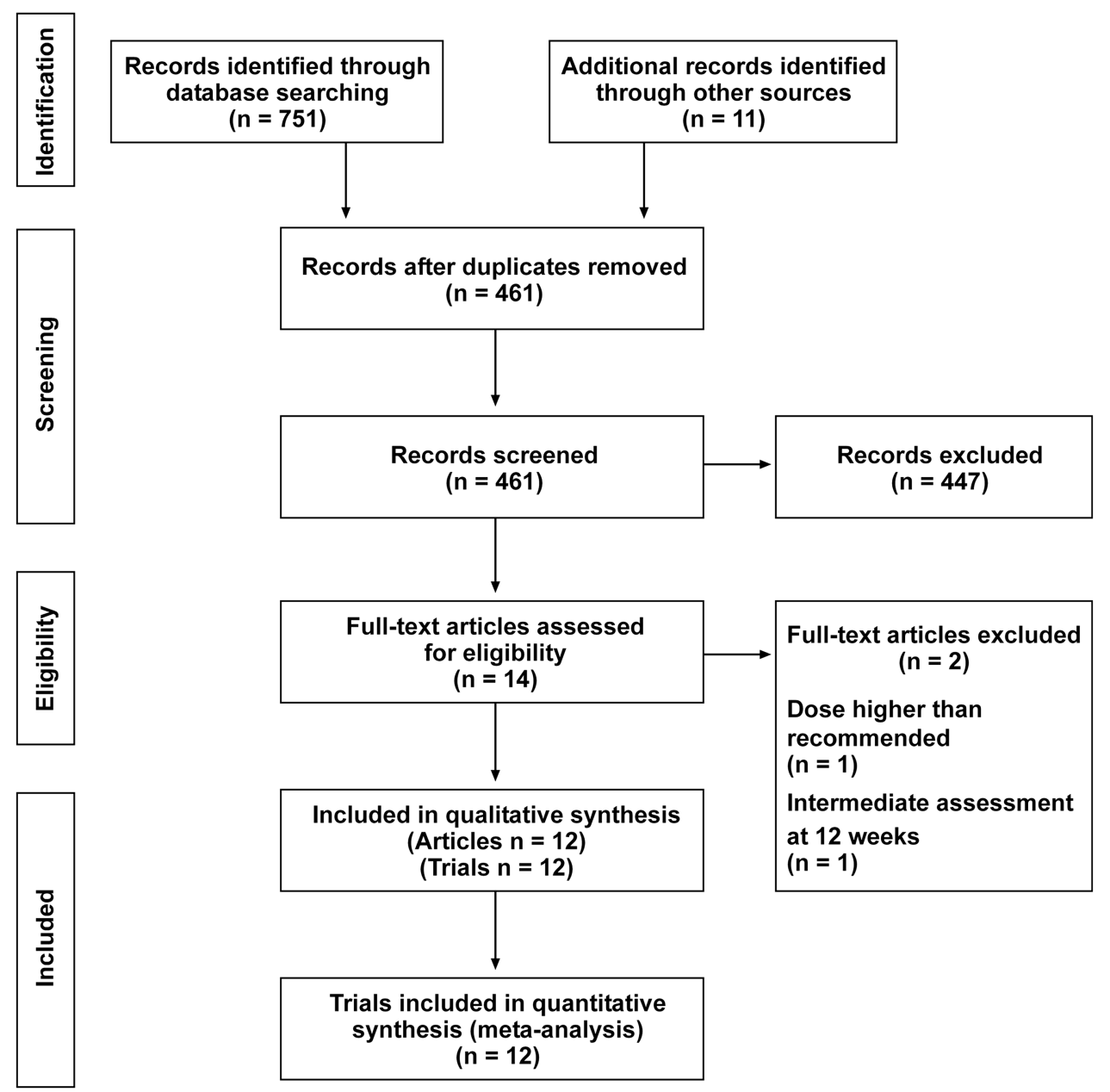

Figure 1 Flow diagram of literature search, screening and selection for analysis.

patients with type 2 diabetes. In five trials, ${ }^{14-162024}$ the DPP-4 inhibitor was added to ongoing metformin treatment; in three trials, the patients were either drug naive $^{1319}$ or suspended the previous treatment ${ }^{21}$; in the remaining four trials, the DPP-4 inhibitor was added to glyburide, ${ }^{22}$ a thiazolidinedione ${ }^{23}$ or to a multiple ${ }^{18}$ or variable $^{17}$ antidiabetic therapy.

\section{Outcomes}

All trials included a definition of the primary outcome, which was the change in HbAlc from baseline to the end of the follow-up in 10 trials. $^{13-16} 19-24$

\section{Risk of bias}

All trials were deemed to have a low risk of selection bias (random sequence generation) and most trials were assessed as having a low risk of attrition bias (figure 2). Most trials provided incomplete information on allocation concealment, blinding of participants and personnel, and blinding of outcome assessment.

\section{Primary outcome}

Trial findings are summarised in table 2. The difference in HbAlc changes between final and intermediate points averaged $0.22 \% \quad(95 \%$ CI $0.15 \%$ to $0.29 \%$, $\mathrm{p}<0.0001)$. There was substantial heterogeneity between the results of trials included in the pooled analysis of the primary outcome $\left(\chi^{2}\right.$ test for heterogeneity, $\mathrm{p}<0.0001 ; \mathrm{I}^{2}=91 \%$ ).

Sensitivity analysis assuming lower (0.25) or higher $(0.75)$ correlation coefficients of variance did not change results $(0.21 \%$ and $0.22 \%$, respectively, $\mathrm{p}<0.0001)$. Subgroup analyses evaluated whether differences existed between primary or extension studies, or if the addition of the DPP-4 inhibitor to metformin behaved differently from the other studies. Estimates of differences were not significantly affected by the analysis of the six extension trials $(0.24 \%, 0.02$ to $0.46, \mathrm{p}=0.036)$, or the five trials in which the DPP-4 inhibitor was added to metformin $(0.24 \%, 0.16$ to $0.32, \mathrm{p}<0.0001$; table 2$)$.

\section{DISCUSSION}

Declining $\beta$-cell function is the predominant reason for deterioration in glucose tolerance and largely explains the difficulty in maintaining target levels of HbAlc with traditional glucose-lowering agents. The idea that DPP-4 inhibitors may alleviate $\beta$-cell death in animal models seems still attractive ${ }^{5}$ and potentially may be associated 


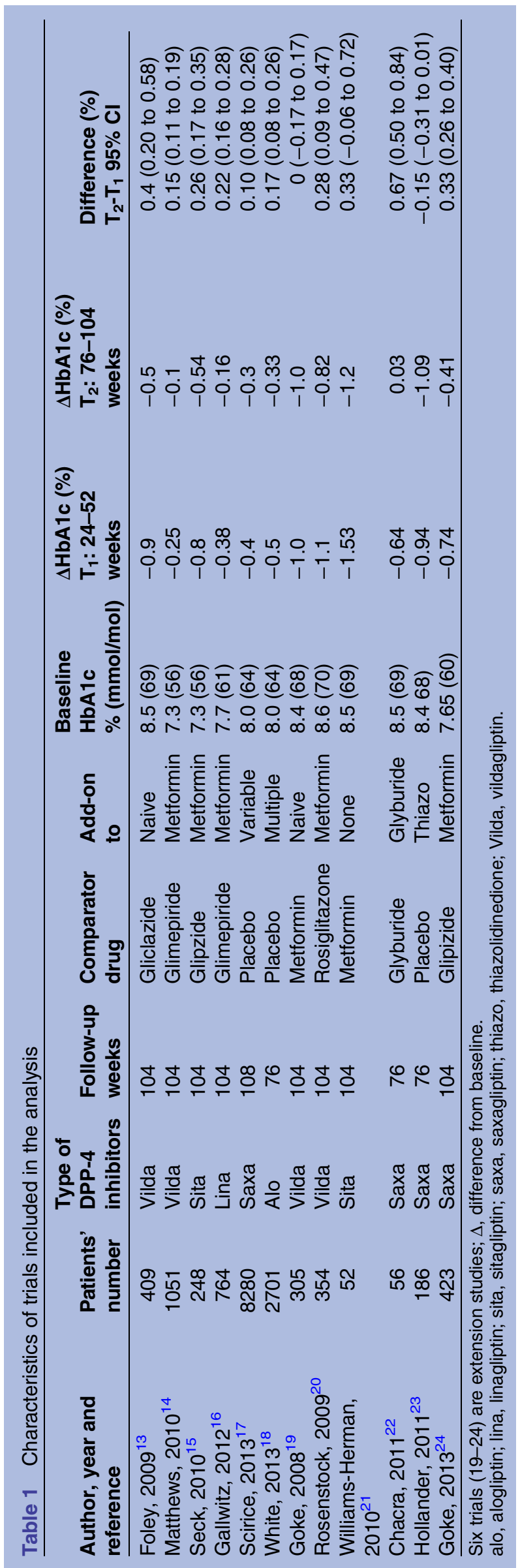

with long glycaemic durability. To the best of our knowledge, no other analysis assessed the glucose-lowering effect of DPP-4 inhibitors as a function of time in studies with long follow-up. We found that HbAlc decrease at the end of treatment with DPP-4 inhibitors was significantly lower than that recorded at intermediate points, suggesting that the glucose-lowering effect of DPP-4 inhibitors declines with time. Although extended trials are more likely to be biased, as those patients who had loss of glycaemic control were not enrolled in the extension part of the randomised trial, extension studies behave as primary studies in terms of glycaemic durability with DPP-4 inhibitors.

The robustness of our analysis is further supported by the results of the two excluded trials. One trial ${ }^{11}$ was a phase 3, double-blind, active-controlled trial with 1306 patients randomised to four different treatments including a saxagliptin ( $10 \mathrm{mg}$ daily) arm; at 76 weeks, adjusted mean change from baseline $\mathrm{HbAlc}$ was $-1.55 \%$, but the highest decrease from baseline occurred at 30 weeks and averaged $-1.9 \%$. The other trial $^{12}$ was a phase IIb, open-label, 78-week extension study of a 12-week blinded trial; in one arm, 56 patients received sitagliptin as add-on to metformin. At 90 weeks, the HbAlc change from baseline was $-0.4 \%$, with the greatest reduction $(-0.58 \%)$ occurring at 18 weeks.

Our study has its limitations. First, a 2-year span is not the optimal time frame to assess glycaemic durability which needs more time. ${ }^{25}$ The Glycemia Reduction Approaches in Diabetes: a comparative Effectiveness (GRADE) study seeks to compare the effects of four drugs (sulfonylureas, DPP-4 inhibitors, glucagon-like peptide 1 receptor agonists and insulin) when combined with metformin in adult patients with recent-onset type 2 diabetes and is focused on glycaemic durability. ${ }^{26}$ Hopefully, the results of GRADE will provide guidance to clinicians about the most appropriate medications to treat type 2 diabetes. However, with recruitment over 3 years and an average follow-up time of 4.8 years, results will be available not before 2019. Second, the heterogeneity of the studies was high; however, the estimates were not affected by sensitivity and subgroup analyses. Third, the number of trials included may be seen as relatively scarce; on the other hand, 12 studies may be enough to have a trend. Finally, the intermediate observation happened over a long period, which can be seen as a limitation; however, we have shown that the relation between the HbAlc response to DPP-4 inhibitors and time is quite linear during the first year of treatment, without differences at any intermediate points $\left(12,24\right.$ or 52 weeks). ${ }^{8}$

In conclusion, the analysis of 12 randomised trials with duration up to 108 weeks suggests that the effect of DPP-4 inhibitors on HbA1c decreases during the second year of treatment. Further research with a longer follow-up hopefully will allow to individualise the characteristics of the diabetic patient who benefits most from DPP-4 inhibitors in terms of glycaemic durability. 
Figure 2 Summary of authors' judgements on the risk of bias in reviewed trials.

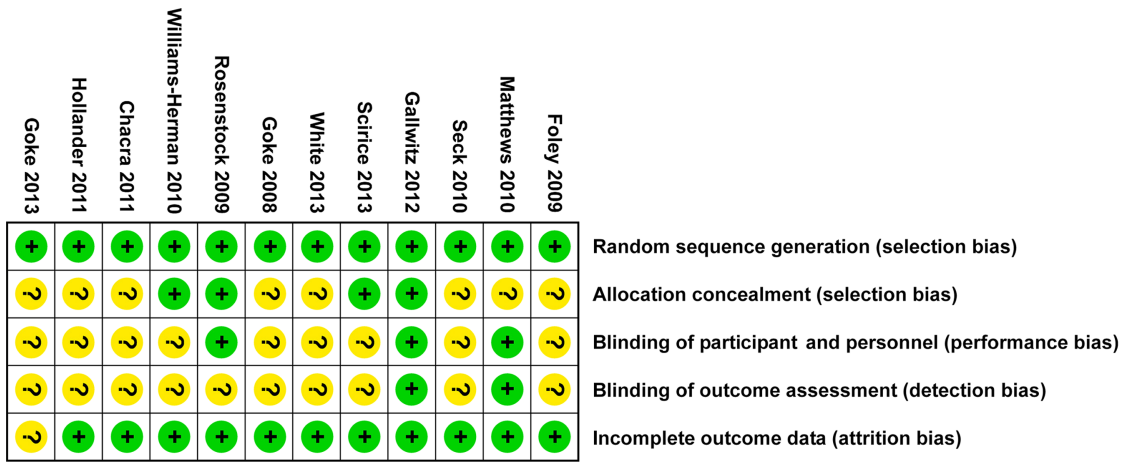

Table 2 Sensitivity and subgroup analyses

\begin{tabular}{|c|c|c|c|c|c|c|c|}
\hline & $\begin{array}{l}\text { Number } \\
\text { of arms }\end{array}$ & $\begin{array}{l}\text { Mean age } \\
(\text { years)* }\end{array}$ & $\begin{array}{l}\text { Mean basal } \\
\text { HbA1c }(\%)^{\star}\end{array}$ & $\begin{array}{l}\text { Pooled } \\
\text { differences } \\
\mathrm{T}_{2}-\mathrm{T}_{1} \mathrm{HbA1c}(\%) \\
(95 \% \mathrm{Cl})\end{array}$ & p Value & $I^{2}(\%)$ & $\begin{array}{l}\mathbf{l}^{2} \\
\mathbf{p} \text { value }\end{array}$ \\
\hline Correlation 0.50 & 12 & 62.2 & 7.96 & $0.22(0.15$ to 0.29$)$ & $<0.0001$ & 91 & $<0.0001$ \\
\hline Correlation 0.25 & 12 & 62.2 & 7.96 & $0.21(0.14$ to 0.29$)$ & $<0.0001$ & 86 & $<0.0001$ \\
\hline Correlation 0.75 & 12 & 62.2 & 7.96 & $0.22(0.15$ to 0.29$)$ & $<0.0001$ & 95 & $<0.0001$ \\
\hline Primary studies† & 6 & 63 & 7.93 & $0.19(0.13$ to 0.25$)$ & $<0.0001$ & 86 & $<0.0001$ \\
\hline Extension studies† & 6 & 54.8 & 8.22 & $0.24(0.02$ to 0.46$)$ & 0.036 & 92 & $<0.0001$ \\
\hline Metformin (add-on to) $†$ & 5 & 57.8 & 7.62 & 0.24 (0.16 to 0.32$)$ & $<0.0001$ & 82 & $<0.0001$ \\
\hline
\end{tabular}

\section{Author affiliations}

${ }^{1}$ Department of Experimental and Clinical Medicine, Second University of Naples, Naples, Italy

${ }^{2}$ Department of Mental and Physical Health and Preventive Medicine, Second University of Naples, Naples, Italy

${ }^{3}$ Department of Medical, Surgical, Neurological, Metabolic and Geriatric Sciences, Second University of Naples, Naples, Italy

${ }^{4}$ Department of Experimental Medicine, Second University of Naples, Naples, Italy

Contributors DG and KE designed the protocol and the methods. PC and DG carried out the statistical analysis. All authors contributed to data extraction, drafting of the article and approved the final version of the manuscript.

Funding This study was funded in part with support from the Second University of Naples, and the Association 'Salute con Stile'.

Competing interests $\mathrm{KE}$ and $\mathrm{DG}$ received consultancy fees, attended advisory boards or have held lectures for a number of pharmaceutical companies producing antidiabetic drugs.

Patient consent Obtained.

Provenance and peer review Not commissioned; externally peer reviewed.

Data sharing statement No additional data are available.

Open Access This is an Open Access article distributed in accordance with the Creative Commons Attribution Non Commercial (CC BY-NC 4.0) license, which permits others to distribute, remix, adapt, build upon this work noncommercially, and license their derivative works on different terms, provided the original work is properly cited and the use is non-commercial. See: http:// creativecommons.org/licenses/by-nc/4.0/

\section{REFERENCES}

1. Esposito K, Bellastella G, Giugliano D. When metformin fails in type 2 diabetes mellitus. Arch Intern Med 2011;171:365-6.
2. Esposito K, Ceriello A, Giugliano D. Does personalized diabetology overcome clinical uncertainty and therapeutic inertia in type 2 diabetes? Endocrine 2013;44:343-5.

3. Turner LW, Nartey D, Stafford RS, et al. Ambulatory treatment of type 2 diabetes mellitus in the United States, 1997-2012. Diabetes Care 2014;37:985-92.

4. Phung OJ, Scholle JM, Talwar M, et al. Effect of noninsulin antidiabetic drugs added to metformin therapy on glycemic control, weight gain, and hypoglycemia in type 2 diabetes. JAMA 2010;303:1410-18.

5. Mu J, Woods J, Zhou YP, et al. Chronic inhibition of dipeptidyl peptidase-4 with a sitagliptin analog preserves pancreatic beta-cell mass and function in a rodent model of type 2 diabetes. Diabetes 2006;55:1695-704.

6. Pratley RE, Schweizer A, Rosenstock J, et al. Robust improvements in fasting and prandial measures of $\beta$-cell function with vildagliptin in drug-naïve patients: analysis of pooled vildagliptin monotherapy database. Diabetes Obes Metab 2008;10:931-8.

7. Liberati A, Altman DG, Tetzlaff J, et al. The PRISMA statement for reporting systematic reviews and metaanalyses of studies that evaluate health care interventions: explanation and elaboration. Ann Intern Med 2009;151:W65-94.

8. Esposito K, Chiodini P, Capuano A, et al. Baseline glycemic parameters predict the hemoglobin A1c response to DPP-4 inhibitors : meta-regression analysis of 78 randomized controlled trials with 20,053 patients. Endocrine 2014;46:43-51.

9. Higgins JPT, Altman DG, Sterne JAC. Chapter 8: assessing risk of bias in included studies. In: Higgins JPT, Green S, eds. Cochrane handbook for systematic reviews of interventions (version 5.1.0) (updated March 2011). The Cochrane Collaboration, 2011. http:// www.cochrane-handbook.org

10. Deeks JJAD, Bradburn MJ. Statistical methods for examining heterogeneity and combining results from several studies in meta-analysis. In: Egger MD-SG, Altman DG, eds. Systematic reviews in health care. London: BMJ Publishing, 2001:285-312.

11. Pfützner A, Paz-Pacheco E, Allen E, et al. Initial combination therapy with saxagliptin and metformin provides sustained glycaemic control and is well tolerated for up to 76 weeks. Diabetes Obes Metab 2011;13:567-76. 
12. Ferrannini E, Berk A, Hantel S, et al. Long-term safety and efficacy of empagliflozin, sitagliptin, and metformin: an active-controlled, parallel-group, randomized, 78-week open-label extension study in patients with type 2 diabetes. Diabetes Care 2013;36:4015-21.

13. Foley JE, Sreenan S. Efficacy and safety comparison between the DPP-4 inhibitor vildagliptin and the sulfonylurea gliclazide after two years of monotherapy in drug-naïve patients with type 2 diabetes. Horm Metab Res 2009;41:905-9.

14. Matthews DR, Dejager S, Ahren B, et al. Vildagliptin add-on to metformin produces similar efficacy and reduced hypoglycaemic risk compared with glimepiride, with no weight gain: results from a 2-year study. Diabetes Obes Metab 2010;12:780-9.

15. Seck T, Nauck M, Sheng D, et al.; Sitagliptin Study 024 Group. Safety and efficacy of treatment with sitagliptin or glipizide in patients with type 2 diabetes inadequately controlled on metformin: a 2-year study. Int J Clin Pract 2010;64:562-76.

16. Gallwitz B, Rosenstock J, Rauch T, et al. 2-year efficacy and safety of linagliptin compared with glimepiride in patients with type 2 diabetes inadequately controlled on metformin: a randomized, double-blind, non-inferiority trial. Lancet 2012;380:475-83.

17. Scirica BM, Bhatt DL, Braunwald E, et al.; SAVOR-TIMI 53 Steering Committee and Investigators. Saxagliptin and cardiovascular outcomes in patients with type 2 diabetes mellitus. $N$ Engl $J$ Med 2013;369:1317-26

18. White WB, Cannon CP, Heller SR, et al.; EXAMINE Investigators. Alogliptin after acute coronary syndrome in patients with type 2 diabetes. N Engl J Med 2013;369:1327-35.

19. Göke B, Hershon K, Kerr D, et al. Efficacy and safety of vildagliptin monotherapy during 2-year treatment of drug-naïve patients with type 2 diabetes: comparison with metformin. Horm Metab Res 2008;40:892-5.

20. Rosenstock J, Niggli M, Maldonado-Lutomirsky M. Long-term 2-year safety and efficacy of vildagliptin compared with rosiglitazone in drug-naïve patients with type 2 diabetes mellitus. Diabetes Obes Metab 2009;11:571-8.

21. Williams-Herman $\mathrm{D}$, Johnson $\mathrm{J}$, Teng R, et al. Efficacy and safety of sitagliptin and metformin as initial combination therapy and as monotherapy over 2 years in patients with type 2 diabetes. Diabetes Obes Metab 2010;12:442-51.

22. Chacra AR, Tan GH, Ravichandran S, et al. Safety and efficacy of saxagliptin in combination with submaximal sulphonylurea versus up-titrated sulphonylurea over 76 weeks. Diab Vasc Dis Res 2011;8:150-9.

23. Hollander PL, Li J, Frederich R, et al. Safety and efficacy of saxagliptin added to thiazolidinedione over 76 weeks in patients with type 2 diabetes mellitus. Diab Vasc Dis Res 2011;8:125-35.

24. Göke B, Gallwitz B, Eriksson JG, et al. Saxagliptin vs glipizide as add-on therapy in patients with type 2 diabetes mellitus inadequately controlled on metformin alone: long-term (52-week) extension of a 52-week randomised controlled trial. Int J Clin Pract 2013:67:307-16.

25. Kahn SE, Haffner SM, Heise MA, et al.; ADOPT Study Group. Glycemic durability of rosiglitazone, metformin, or glyburide monotherapy. N Engl J Med 2006;355:2427-43.

26. Nathan DM, Buse JB, Kahn SE, et al.; GRADE Study Research Group. Rationale and design of the glycemia reduction approaches in diabetes: a comparative effectiveness study (GRADE). Diabetes Care 2013;36:2254-61. 